\title{
Personal carbon trading: a review of research evidence and real-world experience of a radical idea
}

This article was published in the following Dove Press journal:

Energy and Emission Control Technologies

23 October 2014

Number of times this article has been viewed

\author{
Yael Parag' \\ Tina Fawcett ${ }^{2}$ \\ 'School of Sustainability, The \\ Interdisciplinary Center, Herzliya, \\ Israel; ${ }^{2}$ Environmental Change \\ Institute, Oxford University Centre \\ for the Environment, Oxford, UK
}

Correspondence: Yael Parag School of Sustainability, The Interdisciplinary Center, Kanfei Nesharim St, PO Box 167 , Herzliya 46I50, Israel Tel +97299602443 Email yparag@idc.ac.il
Abstract: Personal carbon trading (PCT) is a radical and innovative mitigation approach for the residential and personal transport sectors. PCT is an umbrella term for various downstream cap-and-trade policies, all of which aim to limit carbon emissions within a society by engaging individuals in the process, and could cover more than $40 \%$ of national carbon emissions. This policy idea is unique because it provides an overarching approach to personal emissions from energy use and because it combines a number of mechanisms to drive behavior change: economic, psychological, and social. This paper presents a review of research evidence and real-world experience of PCT. Most of the political interest, research, and experimentation with PCT has taken place in the UK. During 2006-2008, the UK government commissioned a number of studies on PCT, following high-level political interest. It concluded that public acceptability and the cost of the scheme were serious barriers to its introduction. However, a variety of other research work has subsequently demonstrated that public acceptability may not be such a barrier as feared. Nevertheless, there are a number of other barriers, including costs and technical challenges, some adverse distributional effects, and the low carbon capabilities of citizens. Probably the main barrier is the lack of political will currently to consider PCT as a real option. However, opportunities for PCT adoption could open up, particularly if governments fail to meet their carbon reduction targets. PCT is still an idea rather than an implementable policy - more research is needed to develop detailed scheme designs, which can be tested with regards to equity, effectiveness, cost, and efficiency. Other research requirements include understanding public conceptions of fairness in relation to climate change mitigation. Some interesting experimental research on PCT is currently taking place in Norfolk Island, Australia, but many research gaps remain.

Keywords: emission reduction policy, residential energy

\section{Introduction - the need for a more radical approach for emission reduction}

The most recent evidence from the world's scientists reinforces the message that climate change is occurring and that "it is extremely likely that human influence has been the dominant cause of observed warming since the mid-20th century". ${ }^{1}$ At the same time, carbon emissions from energy use, the greatest source of anthropogenic greenhouse gases, have continued to increase at an average of $2 \%$ per year since $1971 .^{2}$ As a consequence, the atmospheric concentration of carbon dioxide has surpassed 400 parts per million for the first time in human history. ${ }^{3}$

National and international efforts to date have failed to reduce carbon emissions to a level likely to ensure the threshold for "dangerous climate change" is not exceeded. The 
International Energy Agency ${ }^{4}$ suggested that a "far-reaching transformation of the global energy system" would be necessary for global emissions cuts sufficient to remain within the $2^{\circ} \mathrm{C}$ temperature target. The agency warned that without a bold change of policy direction, the world will lock itself into an insecure, inefficient, and high-carbon energy system. New approaches to reducing carbon emissions from energy use are clearly needed.

In Europe, the most prominent European Union(EU)-wide policy to reduce emissions is the EU Emission Trading Scheme (EUETS). The EUETS, governed by Directive 2003/87/EC, caps emissions from the EU power and heavy industry sectors. Although criticized (eg, by Spencer and Guérin ${ }^{5}$ ), the EUETS has been successful in terms of high compliance rates with the caps and the acknowledgment of the majority of the managers in the capped sector that the scheme has caused them to reduce emissions. ${ }^{6}$ Yet, the EUETS caps only a limited percentage of the EU total emissions and does not cover emissions from agriculture, waste, residential sector (except for electricity), and transport (other than aviation). As a result, emissions from all energy sources, other than electricity, in the residential sector are not covered by a cap and trade scheme.

Personal carbon trading (PCT) is a radical approach to reducing emissions from energy use in the residential sector. Unlike most current policy, it focuses on individual energy users and locates rights and responsibilities with individuals for their carbon emissions from household energy use and/ or personal travel. PCT is an umbrella term which describes various downstream cap-and-trade policies, which have different detailed rules and system boundaries, but all of which aim to limit carbon emissions within a society by engaging individuals in the process. This concept has been explored in the context of developed countries, particularly the UK where this idea originates and where much of the research, as well as the real-world examination, has been carried out so far.

This review paper summarizes existing research on PCT. It begins with a short introduction to personal emissions, the concept of PCT, the variants of PCT, and the mechanisms through which a PCT scheme could deliver emissions reduction. It continues with a review of the history of PCT in the UK policy arena and discusses public and political acceptability issues as well as the various barriers facing a PCT scheme. The paper concludes with a reflection on what further research is needed to take the idea forward.

\section{What are personal carbon emissions?}

The concept of personal carbon emissions refers to the carbon emissions arising from direct use of energy in the household and for transport/transport services. The reason for bringing together emissions from the residential and transport sectors, which are normally discussed separately, is the focus on the individuals - in their roles as householders and transport users, and as decision-makers. Carbon emissions from energy and fuel use in homes and cars are straightforward to calculate. Calculating carbon emissions from travel by public transport and by air or sea is more complex, but well-researched methodologies exist. ${ }^{7}$ Indirect emissions embodied in the goods and services which individuals buy are not included in this definition of personal carbon emissions, primarily because they are difficult to calculate and account for. So far, very few products have carbon labels showing their embodied emissions, and creating these is complex. ${ }^{8}$ Giving people responsibility for managing their indirect carbon emissions is currently impossible and indeed might never be a practical option. Thus, the boundaries of "personal carbon emissions" are different from popular measures of personal "carbon footprints," which usually try to take some account of embodied emissions.

While the proportion of national emissions which arise from each sector varies between countries, personal carbon emissions and energy use is generally a significant proportion of the total in developed countries. In the UK, for example, personal carbon emissions make up around $42 \%$ of the national total. From these, 30\% arise from space heating, 10\% from water heating, 9\% from appliances, 4\% from lighting, 3\% from cooking, $29 \%$ from personal travel, 12\% from holiday air travel, and $2 \%$ from other travelling. ${ }^{10}$ Preliminary analysis shows personal emissions make up a similar proportion of the national total in Ireland and Denmark. ${ }^{11}$ In the USA, energy use in the residential sector and for personal transport accounts for $38 \%$ of national delivered energy (authors' analysis based on figures in a US Energy Information Administration report ${ }^{12}$ ).

Although personal carbon emissions are individually insignificant, collectively they are very large. Delivering emission reductions by altering millions of individuals' energy-use choices and behavior remains an unmet policy challenge.

\section{Why PCT?}

In order to reduce emissions from the residential and transport sectors, most governments use a range of policy instruments, including minimum efficiency standards, industry voluntary agreements, energy efficiency obligations on energy suppliers, energy labels, financial incentives, research and development support for efficient and renewable technologies, as well as information and advice programs.

Notwithstanding the wide range of policies, programs, and schemes, there seems to be no overarching approach to 
reducing personal energy consumption which could link them together. An integrated approach would create a perceptual and cognitive framework, enabling individuals to integrate understanding across emissions from different activities, and in the context of energy use as it occurs. ${ }^{13}$

Taxing energy or carbon could be considered as an overarching option for delivering carbon mitigation via energy demand reduction across all energy end-uses. Ultimately, taxation is visible to the final energy user as a price rise which consequently leads to demand reduction. However, people do not necessarily react to price signals imposed by taxes in the manner predicted by neoclassical economics. Energy demand has been shown to be inelastic to price rises, ${ }^{14,15}$ thus weakening the effectiveness of taxation schemes in delivering demand reduction.

PCT is an alternative, innovative, and radical overarching policy with a potential to tackle some of the challenges above. As mentioned earlier, PCT is a general term which describes various downstream cap-and-trade policies. Unlike upstream policies which place much of the responsibility for emission reduction on the energy sector, operate at a distance from individuals, and do not require their direct involvement (eg, minimum efficiency standards for products), PCT focuses on energy users themselves. Accordingly, it assigns rights and responsibilities for the carbon emissions from household energy use and/or personal travel to individuals.

Different PCT schemes have been proposed in the last two decades, but none of these is a fully developed policy instrument. Some of the proposed schemes are outline ideas (eg, a proposal for a scheme covering household energy only ${ }^{16}$ ), while others have been developed and investigated in more detail (eg, tradable energy quotas ${ }^{17}$ and personal carbon allowances $\left.{ }^{18}\right)$. The PCT schemes also vary in their inclusiveness, the scope of emissions they cover, the rules and procedures for allocating, surrendering, and trading carbon units, and the level of individual engagement. Table 1 provides a summary of proposed PCT schemes.

Despite variation, the objective of all PCT schemes is to limit the overall carbon emissions within a society by engaging individuals in the process. All the schemes proposed so far share common features: the scheme is mandatory, with no opt-outs; individuals periodically receive a carbon quota for free; for every activity that involves carbon use within the scope of the scheme, allowances are surrendered; the allowances are tradable in a new personal carbon market; and allowances are reduced over time in line with national carbon-reduction commitments.

To be effective, a PCT scheme must be mandatory. However, there have been a few small-scale voluntary
PCT-like schemes, which people joined in order to reduce their personal carbon emissions. Table 2 provides a summary of voluntary PCT-like schemes. Howell, ${ }^{19}$ who examined such voluntary schemes, argues that while people who tend to join such schemes are usually environmentally aware and do not represent the general population, there are insights from this experience that would be relevant for a mandatory PCT scheme. Insights include, for example, controversies which might arise around issues such as what allowance if any - should be given to children, the boundaries of the scheme, the conversion factors used, and the allowances allocation on an equal-per-capita basis. At the same time, Howell's study highlights the benefits to participants of acting within the schemes, including improved carbon visibility and literacy, and social support for behavior change. ${ }^{19}$ It also suggests that further research is needed to better understand trading behavior, which does not necessarily align with the economically rational, and could have implications for carbon market structure and operations.

\section{How could PCT bring about emissions reduction?}

PCT provides an overarching approach to personal emissions. It is unique because it accesses and combines a number of mechanisms to drive behavior change: economic, psychological, and social. ${ }^{13,20}$ The mechanisms of PCT are presented in Figure 1.

The price of carbon provides an economic incentive for reducing emissions. This price would be determined by the market of traded allowances and will be influenced by various factors, including the extent of the "shortage" of allowances, the value of the services carbon-based energy can deliver, and the extent to which there is a well-behaved market. This mechanism penalizes high-emitters while rewarding low-emitters.

The intrinsic psychological mechanism is driven through a combination of the carbon price, the scale of the individual allowance, and the awareness to and the visibility of the carbon emissions related to the individuals' actions. The distribution of allowances between individuals, as well as the personal cap, could influence behavior in different ways than the allowance's total value. Experimental work has provided some indication for a carbon awareness effect on willingness to change behavior ${ }^{20}$ and that people may be inclined to respond to PCT partly based on the absolute size of the allowance and whether they are in credit or debit, rather than responding with pure economic rationality. ${ }^{21}$

The social mechanism relies on the notion that decisions, even about individually allocated resources, are subject to 
Table I A short summary of the variation in proposed personal carbon trading (PCT) schemes

\begin{tabular}{|c|c|}
\hline Scheme & Summary \\
\hline \multirow[t]{10}{*}{ Tradable energy quotas (TEQs) ${ }^{17}$} & Previously known as 'DTQs' (domestic tradable quotas). TEQs is one of the more detailed and developed \\
\hline & proposals. It was proposed and developed in the UK for the UK economy. It aims to tackle climate change \\
\hline & and peak oil. The scope of scheme covers the whole economy. \\
\hline & How it works: a TEQ budget sets a limit on annual carbon emissions over the next 20 years, \\
\hline & which then rolls forward week by week. $40 \%$ of the allowances are distributed free to individuals \\
\hline & on an equal per capita basis. Personal emissions allocations cover household energy use and personal travel, \\
\hline & but not air travel. The remaining $60 \%$ are sold by tender to all other energy users. All fuels \\
\hline & have a carbon rating and purchasers must surrender carbon units to cover related emissions. \\
\hline & Transactions are carried out electronically and all carbon units are tradable. \\
\hline & TEQs scheme has been examined by the UK government in a 'pre-feasibility' study. \\
\hline \multirow[t]{8}{*}{ Cap and Share $(C \& S)^{69}$} & C\&S is one of the more detailed and developed proposals. It was proposed and developed in Ireland \\
\hline & for the Irish economy. The scope of the scheme covers the whole economy. \\
\hline & How it works: an independent committee sets a national carbon cap. All adults periodically receive \\
\hline & certificates entitling them to an equal share of national emissions. Certificates are sold by individuals \\
\hline & via banks or post offices to companies that import or extract fossil fuels. These suppliers require \\
\hline & surrendering certificates equal to emissions from the use of the fossil fuels that they introduce \\
\hline & into the economy. The price of emissions flows through the economy. \\
\hline & C\&S has been examined by the Irish government. \\
\hline \multirow[t]{6}{*}{ Tradable consumption quota ${ }^{70}$} & $\begin{array}{l}\text { The details of this scheme are not particularly well developed. The scope of the scheme covers the whole } \\
\text { economy. }\end{array}$ \\
\hline & How it works: a national cap is set on carbon emissions. All national emissions are allocated for free \\
\hline & to individuals on equal per capita basis. All products would be carbon labelled. Quotas are surrendered \\
\hline & by individuals to cover the emissions related to the non-manufacturing-related carbon content of purchased \\
\hline & goods and their own direct use of energy. Manufacturing organizations buy emissions quotas from individuals \\
\hline & in a carbon market to cover their carbon emissions related to the process of manufacturing. \\
\hline \multirow[t]{8}{*}{ Personal carbon allowances $(\mathrm{PCA})^{18}$} & PCA was proposed and developed in the UK. It is one of the more detailed and developed proposals. \\
\hline & The scope of the scheme covers household energy and personal travel. \\
\hline & How it works: a national cap is set for emissions from household energy use, including air travel. \\
\hline & Allowances and personal are allocated periodically on an equal per capita basis to individuals for free \\
\hline & to cover these emissions. For every transport purchase of electricity, gas, transport fuels and services, \\
\hline & allowances are surrendered. Transactions (PCA) are carried out electronically and allowances are tradable \\
\hline & in the personal carbon market. \\
\hline & PCA has been examined by the UK government in a 'pre-feasibility' study. \\
\hline \multirow[t]{9}{*}{ Household carbon trading ${ }^{16}$} & Household carbon trading was proposed in California and examined against its emission targets. \\
\hline & The details of this scheme are not particularly well developed. \\
\hline & The scope of the scheme covers household energy. \\
\hline & How it works: a yearly carbon emissions cap is set for residential energy use based on emissions reduction \\
\hline & targets. Allowances are allocated to each household on an equal per household allocation basis via utility \\
\hline & service providers who place the allowances in each user's account. These are deducted periodically \\
\hline & by the utility according to energy use, and additional allowances must be purchased if the account \\
\hline & is in deficit. The carbon allowances are fully tradable. At the end of a compliance period, the state collects \\
\hline & the permits from the utilities and determines compliance with the cap. \\
\hline \multirow[t]{8}{*}{ Tradable transport carbon permits ${ }^{71}$} & Tradable transport carbon permits were originally suggested in France and the scheme was examined \\
\hline & for emissions generated by French private transport. It has also been applied to the UK. ${ }^{38}$ \\
\hline & The scope of the scheme covers private road transport. \\
\hline & How it works: a cap is set for emissions from private transport. Allowances are allocated to all individuals \\
\hline & for free (not necessarily on an equal basis). For every purchase of fuel, allowances are transferred \\
\hline & to the regulating authority to cover the $\mathrm{CO}_{2}$ equivalent of a liter of fuel and cancelled. Transactions \\
\hline & and trading are carried out electronically. \\
\hline & Participants buy and sell permits through intermediates like banks or buy them at the petrol pump. \\
\hline
\end{tabular}

Note: Copyright (2010. Adapted from Fawcett T, Parag Y. An introduction to personal carbon trading. Clim Policy. 20I0;I0(4):329-338, with permission from Taylor \& Francis Ltd, www.tandfonline.com. ${ }^{68}$

social forces ${ }^{22}$ and that energy conservation arising from normative concern - as opposed to hedonistic or cost reasons - is more robust against changes and therefore more durable. ${ }^{23}$ The carbon "budget" allocated to individuals suggests, to some extent, an acceptable and fair personal carbon footprint. As such, it provides an indication and guidelines for the level of personal emissions that would not harm the atmosphere.

The interaction between these mechanisms and the overall impact of the policy will be contingent upon a range 
Table 2 Voluntary personal carbon trading (PCT)-like schemes

\begin{tabular}{|c|c|}
\hline Scheme & Summary \\
\hline Grassroots & In the UK the grassroots movement Carbon Rationing Action Groups (CRAGs) operated a PCT-like scheme. CRAGs \\
\hline PCT-like schemes & $\begin{array}{l}\text { were community-based groups (8-12 members on average) that voluntarily agreed to ration personal carbon emissions } \\
\text { and act to reduce them against the pre-set carbon targets. The different CRAGs schemes varied: some were more } \\
\text { ambitious than other, some covered aviation while other did not, some included a financial penalty for not meeting } \\
\text { the target, and some did not. On } 2009 \text { there were } 24 \text { groups listed on the UK CRAG website as 'active'. Since then, } \\
\text { however, most of the CRAGs have ceased to exist. }{ }^{19}\end{array}$ \\
\hline Work place & In 2008, WSP, an international engineering and environmental consultancy company, launched 'PACT' a personal carbon \\
\hline PCT-like scheme & $\begin{array}{l}\text { allowance tracking scheme for its employees around the UK. This PCT-like program set staff an annual carbon allowance } \\
\text { and tracked their performance against it. The program included a bonus for those who came under their targets and } \\
\text { a penalty (maximum } \mathrm{f} 100 \text { ) for those who exceeded it. Today WSP sells the PACT as a service to other organizations. } \\
\text { According to the WSP website, the voluntary carbon allowance scheme has helped around } 4,000 \text { employees to cut their } \\
\text { carbon footprints by an average of } 10 \text { per cent. }{ }^{72,73}\end{array}$ \\
\hline
\end{tabular}

of other factors related to the design of the scheme and its public support. The same broad assessment might be made of carbon taxes as a policy instrument. However, while carbon taxes are designed primarily to target economic behavior, through changing prices within existing markets and social frameworks, PCT is more likely to impact via the other mechanisms too because of the use of a new carbon market, budgets, and the potential for social and institutional change. ${ }^{20}$

It is important to note that PCT is not envisaged as replacing most current policies. Rather, it could be seen as an enabling policy which is likely to push individuals to make the most of existing schemes, such as product and building standards, energy labels, taxation and financial incentives, ${ }^{24,25}$ as well as low carbon transport modes. ${ }^{26}$

\section{Public and political acceptability of PCT}

From the start of research into PCT, there has been concern about whether this type of policy could be publicly or politically acceptable. This is not surprising given its radical nature.

PCT has attracted political interest in the UK, particularly during 2006-2008. Serious interest was kick-started in 2006 by the Secretary of State for the Environment, promoting it as a possible policy option in the context of all parts of society needing to make a contribution to

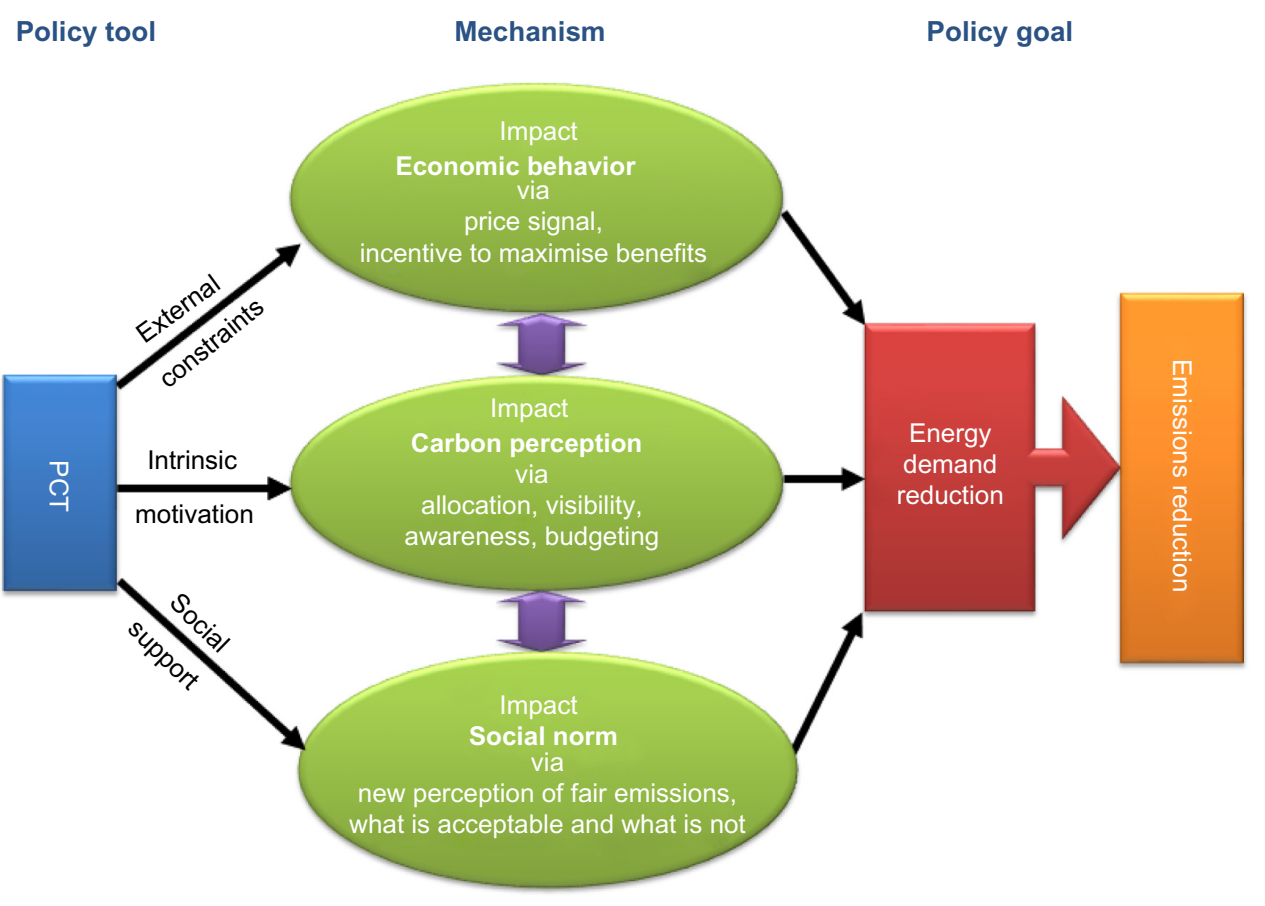

Figure I PCT mechanisms.

Note: Copyright @2009. Environmental Change Institute, University of Oxford. Adapted from Parag Y, Strickland D. Personal Carbon Budgeting: What people need to know, learn and have in order to manage and live within a carbon budget, and the policies that could support them. UKERC Research Report, Demand Reduction Theme. 2009.13 
reducing carbon emissions. ${ }^{27}$ Although PCT had gained some previous political attention, this had not led to much public discussion, whereas in 2006-2007, there was considerable reporting of the ideas in the press, and discussion about its pros and cons. ${ }^{28}$

The Secretary of State's interest led to a program of research work being commissioned by the Department for Environment, Food and Rural Affairs (Defra). In 2008, Defra published four reports regarding PCT, which covered its technical feasibility and potential cost, effectiveness and strategic fit, public acceptability, and distributional impacts. In its synthesis report, based on the research it had commissioned, Defra concluded that PCT was ahead of its time. ${ }^{29}$ The key concerns were public acceptability and costs, with doubts of whether these issues could be resolved satisfactorily. Defra concluded that the government should remain engaged in the debate around PCT, but that further work should be taken forward by academics and research organizations and not the government itself.

However, the House of Commons Environmental Audit Committee, an influential committee of members of parliament, which published its report a month later, was more supportive of PCT, and "regretted" Defra's decision to wind down further research work on PCT. ${ }^{30}$ Their inquiry concluded that PCT could be "essential" in helping to reduce national carbon emissions, and that further research was urgently required. However, the government did not take the committee's advice, and there has been no further government-sponsored research on PCT.

In general, there has been little political interest in other countries. In Ireland, "Cap and Share" (see Table 1) has been investigated by the Sustainable Development Council, ${ }^{31}$ but this has not led to wider government interest in the scheme.

A number of studies have explored public response to PCT. These have used a wide range of methodologies, including focus-group discussions, ${ }^{32,33}$ presenting participants with personalized information about the impact of different policies based on their actual carbon footprints, ${ }^{34}$ semi-structured interviews, ${ }^{35}$ questionnaire surveys, ${ }^{36}$ and an opinion poll. ${ }^{37}$ Other studies have used mixed methods. ${ }^{38}$ Questions about PCT have been asked in the context of all personal energy use, for transport emissions only, and in comparison with other policies, or as a stand-alone policy.

The range of methods, and the fact that they have been used with different scheme designs, adds weight to the collective conclusion that when PCT is compared with carbon taxation (or other policies) it is usually preferred. For those who prefer PCT, its key benefits are seen as fairness and effectiveness, where fairness is understood in terms of the distributional effects of the policy (who loses and who gains) as well as the "equal rights" principle PCT embodies. For those against, their main concerns are about implementation and unfairness. There is concern about different sorts of unfairness. Some people object to the idea, embodied in PCT, that high polluters can pay to continue their high carbon lifestyles. Others worry that there would be vulnerable losers, without the resources to adopt a low carbon lifestyle (eg, investing in energy efficiency). Another source of unfairness is that the existing infrastructure does not always permit low carbon choices (eg, lack of public transport in rural areas).

Seeking views on a hypothetical policy, whose details have not yet been fully worked out, is somewhat problematic, and care needs to be taken in interpretation of results. The criteria that people raise as guiding their decisions on PCT and other policies (fairness, effectiveness, and implementation) are important in understanding their views. Fairness is a key issue, and in practice, the fairness of PCT would depend on detailed policy design, implementation, and enforcement, as well as the principles on which it is based. Therefore, while the evidence points to public acceptability not being an overwhelming barrier to the uptake of PCT, scheme design would need to deliver the benefits expected by those in favor, and allay the fears of those against, to achieve public support.

\section{Barriers and opportunities for PCT}

Barriers and obstacles to PCT can be divided into two categories: 1) barriers related to technical and economic feasibility of the scheme, and 2) barriers related to ideology, values, and beliefs about fairness and about the role, responsibility, and capability of individuals versus government and industry in climate-mitigation efforts.

PCT not only presents a different approach to pricing carbon, it also runs contrary to the conventional wisdom in the policy community about the extent to which governments can and should challenge personal consumption. ${ }^{39}$ As such, PCT is perceived by policymakers as a political risk. ${ }^{40}$ Adding to this political risk is the fact that PCT is innovative and radical, and while promising, its feasibility and effectiveness have never been demonstrated or tested. And even if a PCT simulation was trialed, only limited aspects could actually be tested before launching it. ${ }^{41}$

Examination of the technical and operational feasibility of PCT suggests that the know-how to establish a database system to securely hold and manage personal carbon "accounts" 
exists: the existing infrastructure for credit and debit card transactions could be used for carbon credit transactions. ${ }^{42}$ Likewise, fraud prevention and enforcement are possible. ${ }^{43}$ Both fraud prevention and enforcement details would depend on the level of enforcement: upstream, at the energy utility level, or downstream, at the individual level. ${ }^{44} \mathrm{~A}$ trial using loyalty cards to track fuel purchases at petrol stations and generate carbon emissions figures, showed that this was feasible and that it cost less than had been thought. ${ }^{45}$ Most feasibility studies were done nearly a decade ago. In the last decade, however, information technology and information security have improved dramatically. Today, electronic transactions of money and information are widely used on a daily basis. It would be reasonable to assume that there should not be a significant technical barrier to implementing a PCT scheme.

The cost of introducing, running, and enforcing PCT could be a significant barrier. Costs would depend very much on the scheme structure and the implementation details. ${ }^{42,43,46} \mathrm{~A}$ study commissioned by Defra ${ }^{47}$ suggested that PCT annual running costs could be $£ 20-£ 40$ per adult, in addition to one-off startup costs of $£ 14-£ 40$ per person. Lockwood ${ }^{48}$ and the Lean Economy Connection ${ }^{49}$ questioned some of the underlying assumptions about the cost of the scheme and suggested that the costs might only be half those suggested by Defra.

Moving from technical and economic barriers to those based more on values or ideology, the fairness of PCT is a key concern. PCT embodies a specific view of equity: it suggests that an equal allowance is fair. This is based on a "rights" interpretation of fairness, but some would argue that a "capability" basis (eg, ability to reduce emissions, or ability to pay), or even efficiency (most carbon savings at least cost) would be more just. For a philosophical interrogation of these issues, see Starkey ${ }^{50,51}$ and Hyams. ${ }^{52}$ Practically and technically, allocation of equal allowances has clear benefits over a system based on individual capability. However, PCT scheme design is likely to be strongly influenced by (competing) interpretations of fairness.

In the UK, there has been modeling work looking at the distributional consequences of PCT for different sections of the population and how this varies with the design of PCT policy. The most detailed early work on this was carried out by Ekins and Dresner. ${ }^{53}$ This analysis was updated by Thumim and White, ${ }^{54}$ who looked at the distribution of high and low carbon emitters by income, geographical location, and household composition. They found that $71 \%$ of households in the lowest three income deciles would be "winners" under PCT, while 55\% of households in the highest three income deciles would either have to buy allowances or reduce their emissions (making them "losers"). The authors identified 2.1 million low-income "loser" households (from a total of 24.6 million UK households), many of whom live in rural areas and many also live in larger-than-average homes. Further work looked at the potential for moderating the negative social effects of PCT and showed the positive distributional effect of giving children a proportion of the adult allowance. ${ }^{55,56}$ The overall finding is that PCT is generally progressive but that there will be some low-income losers. Their numbers can be reduced by careful policy design, but these might pose administrative and feasibility challenges.

PCT places responsibility to reduce emissions on individuals and suggests that carbon "budgeting" and trading may cause people to become more aware of their personal emissions, more engaged with emissions reductions, and more inclined to make an effort to reduce them. ${ }^{42}$ There is, however, concern about whether individuals are "carbon capable" (ie, whether they would be able to make informed judgments and take effective decisions regarding the use and management of their own carbon emission budget). ${ }^{25,43,57}$

PCT can be framed and presented in a number of ways and this is reflected in the variety of names used in different versions of the idea: carbon rations, allowances, quotas, tradable permits, and cap and share. The "carbon ration" framing was used by some early proponents ${ }^{58}$ and taken up by the network of voluntary Carbon Rationing Action Groups (Table 2). While some people find this framing attractive, drawing on values of social solidarity and collective responses to external threats, other find it negative, with connotations of austerity and government control. Most advocates tend not to use the language of rationing, for fear of evoking a negative response. ${ }^{59}$ There is also the wider issue about the effect of using a war metaphor in relation to climate change. ${ }^{60}$ Other framings - such as PCT - can also garner a negative response, with concern about the legitimacy of treating carbon as a tradable commodity. ${ }^{61}$ Framing and use of language is clearly important in terms of communication and persuasion, and the wrong framing could damage public and political perception of PCT.

A further criticism of PCT is that it will discourage people from spending money and hence will slow economic growth and reduce the UK competitive advantage compared with places where no such constraint exists. ${ }^{39}$

But maybe the most significant barrier for PCT in the policy arena is the lack of political will to consider it as a real option. In fact, despite the risk of the UK government not delivering its own long-term carbon-reduction targets, 
currently there is no actor within or outside the government who actively advocates PCT or any other mitigation policy that places some of the responsibility to act on individuals. Non-governmental organizations, too, do not advocate it, and this might be because they fear that proposing solutions that rely on civil society action risks "letting Government off the hook". ${ }^{39,62}$

While there are many barriers to the adoption to PCT, there are also opportunities. PCT is more likely to be considered seriously if other policies were seen to be failing at a time when there exists a political pressure to act more radically on climate change ${ }^{39,40}$ Political pressure for PCT could arise from the public (bottom up) or from the international arena (top down), or both. Once in a while, there are calls for the government to consider PCT as a policy option. For example, in 2008, the UK House of Commons' Environmental Audit Committee urged the government to introduce a PCT scheme, arguing that "personal carbon trading might be the kind of radical measure needed to bring about behavioral change."30 Likewise, following the failure of Copenhagen, there were calls (eg, in Doran ${ }^{63}$ ) for policymakers to seriously consider a PCT scheme for the UK in order to bring about a step change in sustainable consumption policy. So far, none of the calls have been accompanied by any significant public or international pressure.

Agreeing with Defra, ${ }^{29}$ Bird and Lockwood $^{40}$ say this might not be the time for a PCT scheme. However, they suggest that policymakers should keep PCT on the shelf as "plan B." They advise the government to prepare the ground for the introduction for PCT by improving the public's carbon literacy and better understand how the public perceives fairness and climate change.

\section{Ongoing research and interest in $\mathrm{PCT}$, and research gaps}

While research on PCT continues to be published (eg, Zanni et $\mathrm{al}^{64}$ and McNamara and Caulfield ${ }^{65}$ ), there are no large-scale research programs about PCT within the EU, to the authors' knowledge. However, there is interesting research currently happening on an island $1,500 \mathrm{~km}$ off the coast of Australia. Norfolk Island is undertaking "the first real test of personal carbon trading in the world" for the Norfolk Island Carbon/Health Evaluation Study (NICHE). The trial is in its early stages, but already, 350 people are registered for it, there is an electronic carbon accounting system, feedback on carbon emissions, and rewards for participation. ${ }^{66}$ The research goals are 1) to test attitudes (and hence acceptability) of an incentive scheme for saving energy and reducing a community's carbon footprint, and 2) to test the hypothesis that increasing people's environmental consciousness will have a positive impact on their health through better health behaviors (ie, more exercise and healthy diet).

There has been some interest in PCT ideas from the commercial sector. For example, Coca-Cola in collaboration with the UK's Carbon Trust have published research on PCT. They expanded the boundaries of personal carbon to include the embodied carbon in food and drink and in leisure activities (as well as household and travel energy use), and trialed the concept of a "personal daily carbon allowance" with a sample of households. ${ }^{67}$ For another example of commercial sector interest, see Table 2.

As this paper has emphasized, considerable political and societal change would be needed for PCT to make the transition from an idea to an adopted policy. However, further research is also required to fully explore the case for PCT. There is a need for further development of detailed PCT policies whose likely effects in terms of equity, efficiency, cost, and acceptability can be tested. Many design options need to be considered, including allocation rules (do children get an allowance, and if so, how much?), banking and accounting, boundaries of the scheme, and compensation to vulnerable "losers" under the scheme. A wide range of research approaches should be involved to test policy designs, including researching voluntary PCT and similar schemes, laboratory experiments, research trials, modeling and qualitative, deliberative methods. A better understanding of people's current carbon capability is needed, as is understanding of how to best inform and motivate people to make lower carbon choices (with or without a PCT scheme). Methods of improving carbon capability should also be researched. How people would actually manage a carbon allowance or trade within a market is currently not understood, and this too needs to be explored. Finally, understanding public interpretations of fairness in energy and climate change policy is vital. Without new and detailed multidisciplinary research, it seems unlikely that PCT will attract significant public or political interest.

\section{Summary and conclusion}

The urgent need for increased action to reduce carbon emissions from developed countries is unarguable. PCT has the potential to tackle a significant proportion of emissions in these countries. It can provide an overarching approach to carbon emissions reduction in the residential and transport sectors and accesses psychological, social, and economic mechanisms to engage individuals. It explicitly involves 
citizens in meeting the carbon reduction targets their governments have signed up to.

The UK government said "no" to PCT after a pre-feasibility study and essentially took it off the list of optional mitigation policies. There is no doubt, however, that for developed nations with ambitious carbon reduction goals, innovative and radical policies, including PCT, need to be developed.

PCT is a powerful idea, but at present there is neither a detailed policy design nor sufficient research to indicate that PCT is likely to be an effective, efficient, and equitable policy. More detailed research is needed into a variety of PCT policy designs. Such research would also answer many questions about options for significantly reducing emissions from the residential energy use and personal-travel sectors.

\section{Disclosure}

The authors report no conflicts of interest in this work.

\section{References}

1. Intergovernmental Panel on Climate Change. Summary for policymakers. In: Stocker T, Qin D, Plattner GK, et al, editors. Climate Change 2013: The Physical Science Basis. Contribution of Working Group I to the Fifth Assessment Report of the Intergovernmental Panel on Climate Change. UK: Cambridge; 2013.

2. OECD. OECD Factbook 2013: Economic, Environmental and Social Statistics. Paris: OECD; 2013.

3. Scripps Institution of Oceanography. The Keeling Curve: carbon dioxide observations at Mauna Loa Observatory. 2104. Accessed May 14, 2014.

4. International Energy Agency. World Energy Outlook 2010 Factsheet. Paris: International Energy Agency; 2011.

5. Spencer T, Guérin E. Time to Reform the EU Emissions Trading Scheme. European Energy Review. 2012;23.

6. Tvinnereim E, Zelljadt E, YakymenkoN, Mazzacurati E. Carbon 2011. Oslo: Thomson Reuters Point Carbon; 2011. http://www.pointcarbon. com/polopoly_fs/1.1545244!Carbon\%202011_web.pdf. Accessed August 25, 2014.

7. JMP, Department for Transport, Department for the Environment Food and Rural Affairs. Measuring and Reporting Greenhouse Gas Emissions A Department for Transport Guide to Work-Related Travel. London: JMP, Department for Transport, Department for the Environment Food and Rural Affairs; 2011.

8. Boardman B. Carbon labelling: too complex or will it transform our buying? Significance. 2008;5(4):168-171.

9. Nature Conservancy. What's my carbon footprint? Accessed May 10, 2014.

10. HM Government. Meeting the Energy Challenge: a UK white paper on energy. London: The Stationery Office; 2007.

11. Fawcett T. Personal carbon trading in different national contexts. Climate Policy. 2010;10(4):339-352.

12. EIA. Annual Energy Outlook with Projections to 2014. Washington DC: USA: Energy Information Administration, US Department of Energy; 2014.

13. Parag Y, Strickland D. Personal Carbon Budgeting: What people need to know, learn and have in order to manage and live within a carbon budget, and the policies that could support them. UKERC Research Report, Demand Reduction Theme. 2009.

14. Halvorsen B, Larsen BM. The flexibility of household electricity demand over time. Resource Energy Econ. 2001;23(1):1-18.

15. Reiss PC, White MW. Household electricity demand, revisited. Rev Econ Stud. 2005;72(3):853-883.
16. Niemeier D, Gould G, Karner A, et al. Rethinking downstream regulation: California's opportunity to engage households in reducing greenhouse gases. Energy Policy. 2008;36:3436-3447.

17. Fleming D. Energy and the Common Purpose: Descending the Energy Staircase with Tradable Energy Quotas (TEQs). London: The Lean Economy Connection; 2007.

18. Hillman M, Fawcett T. How We Can Save the Planet. London: Penguin Books; 2004.

19. Howell R. Living with a carbon allowance: the experiences of Carbon Rationing Action Groups and implications for policy. Energy Policy. 2012;41:250-258.

20. Parag Y, Capstick S, Poortinga W. Policy attribute framing: a comparison between three policy instruments for personal emissions reduction. J Policy Anal Manage. 2011;30(4):889-905.

21. Capstick SB, Lewis A. Effects of personal carbon allowances on decision-making: evidence from an experimental simulation. Climate Policy. 2010;10(4):369-384.

22. Schultz PW, Nolan JM, Cialdini RB, Goldstein NJ, Griskevicius V. The constructive, destructive, and reconstructive power of social norms. Psychol Sci. 2007;18(5):429-434.

23. Lindenberg S, Steg L. Normative, gain and hedonic goal frames guiding environmental behavior. J Soc Issues. 2007;63(1):117-137.

24. Kerr A, Battye W. Personal Carbon Trading: Economic Efficiency and Interaction with Other Policies. London: Royal Society for the Encouragement of Arts; 2008.

25. Parag Y, Strickland D. Personal Carbon Budgeting: UKERC working paper UKERC/WP/DR/2009/014. Oxford: UKERC; 2009.

26. Department for Transport. Visioning and Backcasting for UK Transport Policy (VIBAT): Stage 3 Report, Policy Packaging and Pathways. Department for Transport; 2006.

27. Miliband DE. Food and rural affairs. London: House of Commons Debate December 14, 2006: Hansard; 2006.

28. Fawcett T. Personal carbon trading: is now the right time? Carbon Manag. 2012;3(3):283-291

29. Department for Environment Food and Rural Affairs. Synthesis Report on the Findings from Defra's Pre-Feasibility Study into Personal Carbon Trading. London: Department for Environment Food and Rural Affairs; 2008

30. Environmental Audit Committee. Personal Carbon Trading. London: The Stationery Office; 2008.

31. Comhar SDC Sustainable Development Council. A Study in Personal Carbon Allocation: Cap and Share. Dublin: Comhar SDC Sustainable Development Council; 2008.

32. Low R. An Investigation into the Public Acceptability of the Personal Carbon Allowances Proposal for Reducing Personal Greenhouse Gas Emissions [master's thesis]. Edinburgh, UK: Edinburgh University; 2005.

33. Howell R. Would Personal Carbon Allowances be Acceptable to the UK Public as a Means of Reducing Individuals 'Carbon Dioxide Emissions? [master's thesis]. Edinburgh, UK: University of Edinburgh; 2007.

34. Bristow AL, Zanni AM, Wardman M, Chinatakayala PK. Personal Carbon Trading: Using Stated Preference to Investigate Behavioural Response. UK: Loughborough University and University of Leeds; 2008.

35. Wallace AA, Irvine KN, Wright AJ, Fleming PD. Public attitudes to personal carbon allowances: findings from a mixed-method study. Climate Policy. 2010;10(4):385-409.

36. Jagers SC, Löfgren A, Stripple J. Attitudes to personal carbon allowances: political trust, fairness and ideology. Climate Policy. 2010;10(4):410-431.

37. Bird J, Jones N, Lockwood M. Political Acceptability of Personal Carbon Trading: Findings from Primary Research. London: Institute for Public Policy Research; 2009.

38. Harwatt H. Reducing Carbon Emissions from Personal Road Transport through the Application of a Tradable Carbon Permit Scheme: Empirical Findings and Policy Implications from the UK. Leipzig: International Transport Forum; 2008. 
39. Parag Y, Eyre N. Barriers to personal carbon trading in the policy arena. Climate Policy. 2010;10(4):353-368.

40. Bird J, Lockwood M. Plan B? The Prospects for Personal Carbon Trading. London: Institute of Public Policy Research; 2009.

41. Fawcett T, Bottrill C, Boardman B, Lye G. Trialling Personal Carbon Allowances. Oxford, UK: Environmental Change Institute; 2007.

42. Starkey R, Anderson K. Domestic Tradable Quotas: a Policy Instrument for Reducing Greenhouse Gas Emissions from Energy Use. Technical Report 39. East Anglia, UK: Tyndall Centre for Climate Change Research; 2005.

43. Roberts S, Thumim J. A Rough Guide to Individual Carbon Trading: the Ideas, the Issues and the Next Steps. Bristol: Centre for Sustainable Energy; 2006.

44. Eyre N. Policing carbon: design and enforcement options for personal carbon trading. Climate Policy. 2010;10(4):432-446.

45. Prescott M. A Persuasive Climate: Personal Trading and Changing Lifestyles. London: Royal Society for the Encouragement of Arts; 2008.

46. Lockwood M. The economics of personal carbon trading. Clim Policy. 2010;10(4):447-461.

47. Lane C, Harris B, Roberts S. An Analysis of the Technical Feasibility and Potential Cost of a Personal Carbon Trading Scheme: a Report to the Department for Environment, Food and Rural Affairs, Accenture, with the Centre for Sustainable Energy (CSE). London: Department for Environment, Food and Rural Affairs; 2008.

48. Lockwood M. A Review of Assumptions in Defra's Assessment of the Potential Effectiveness of Personal Carbon Trading. London: Institute for Public Policy Research; 2009.

49. Lean Economy Connection. Defra's Pre-Feasibility Study into Personal Carbon Trading: a Missed Opportunity. London: Lean Economy Connection; 2008.

50. Starkey R. Assessing common(s) arguments for an equal per capita allocation. Geogr J. 2011;117(2):112-126.

51. Starkey R. Allocating Emissions Rights: are Equal Shares Fair Shares? Norwich, UK: Tyndall Centre for Climate Change Research; 2008.

52. Hyams K. A just response to climate change: personal carbon allowances and the normal-functioning approach. $J$ Soc Philos. 2009;40: 237-256.

53. Ekins P, Dresner S. Green Taxes and Charges: Reducing their Impact on Low-Income Households. York, UK: Joseph Rowntree Foundation; 2004.

54. Thumim J, White V. Distributional Impacts of Personal Carbon Trading, Report to the Department for Environment, Food and Rural Affairs. London: Department for Environment, Food and Rural Affairs; 2008.

55. Centre for Sustainable Energy. Moderating the Distributional Impacts of Personal Carbon Trading. Report to the Institute for Public Policy Research. Bristol, UK: Centre for Sustainable Energy; 2009.

56. Gough I, Abdallah S, Johnson V, Ryan-Collins J, Smith C. The Distribution of Total Greenhouse Gas Emissions in the UK and Some Implications for Social Policy. CASE Paper/152. London: London School of Economics; 2012.
57. Whitmarsh L, Seyfang G, O’Neill S. Public engagement with carbon and climate change: to what extent is the public 'carbon capable'? Glob Environ Change. 2011;21(1):56-65.

58. Roodhouse M. Rationing returns: a solution to global warming? London: History and Policy; 2007. Available from: http://www.historyandpolicy. org/policy-papers/papers/rationing-returns-a-solution-to-globalwarming. Accessed August 26, 2014

59. Seyfang G, Lorenzoni I, Nye M. Personal Carbon Trading: a Critical Examination of Proposals for the UK. Working Paper 136. Norwich, UK: Tyndall Centre for Climate Change Research; 2009.

60. Cohen MJ. Is the UK preparing for "war"? Military metaphors, personal carbon allowances, and consumption rationing in historical perspective. Climatic Change. 2011;104(2):199-222.

61. Spaargaren G, Mol APJ. Carbon flows, carbon markets, and low-carbon lifestyles: reflecting on the role of markets in climate governance. Environ Politics. 2013;22(1):174-193.

62. Neslen A. Special report - Tory MP calls for personal carbontrading scheme. Brussels: EurActive; 2012. Available from: http:// www.euractiv.com/specialreport-prods-green-planet/pioneeringtory-mp-calls-persona-news-513659\#channel=f28bf3bfc2b57\&origi $\mathrm{n}=\mathrm{http} \% 3 \mathrm{~A} \% 2 \mathrm{~F} \% 2 \mathrm{~F}$. Accessed May 16, 2014.

63. Doran PF. After Copenhagen: bringing personal carbon trading home. Glob Justice Sustain Dev. 2010:341-362.

64. Zanni AM, Bristow AL, Wardman M. The potential behavioural effect of personal carbon trading: results from an experimental survey. J Environ Econ Policy. 2013;2(2):222-243.

65. McNamara D, Caulfield B. Examining the impact of carbon price changes under a personalised carbon trading scheme for transport. Transp Policy. 2013;30:238-253.

66. NICHE [homepage on the Internet]. What is NICHE? 2014. Available from: http://www.norfolkislandcarbonhealthevaluation.com. Accessed May 10, 2014.

67. Carbon Trust Advisory, Coca-Cola Company. Personal Carbon Allowances White Paper: How to Help Consumers Make Informed Choices. Carbon Trust Advisory and Coca-Cola Company; 2012.

68. Fawcett T, Parag Y. An introduction to personal carbon trading. Clim Policy. 2010;10(4):329-338.

69. FEASTA. Cap and Share: a Fair Way to Cut Greenhouse Gas Emissions. The Foundation for the Economics of Sustainability: FEASTA; 2008.

70. Ayres R. Environmental market failures: are there any local marketbased corrective mechanisms for global problems? Mitigation Adapt Strategies Glob Change. 1997;1:289-309.

71. Raux C, Marlot G. A system of tradable $\mathrm{CO}_{2}$ permits applied to fuel consumption by motorists. Transp Policy. 2005;12:255-265.

72. WSP Environment and Energy [homepage on the Internet]. Make a Green Impact today. 2010. Available from: http://www.wsppact.com/ sites/pact/home.php. Accessed May 15, 2014

73. WSP [homepage on the Internet]. PACT. New York: WSP USA; 2013. Available from: http://www.wspgroup.com/en/WSP-USA/Who-weare-USA/Sustainability/PACT. Accessed May 15, 2014.
Energy and Emission Control Technologies

\section{Publish your work in this journal}

Energy and Emission Control Technologies is an international, peer-reviewed, open access journal publishing original research, reviews, editorials and commentaries on developing technologies to optimize energy production and control of emissions. The manuscript management system is completely online and includes

\section{Dovepress}

a very quick and fair peer-review system, which is all easy to use. Visit http://www.dovepress.com/testimonials.php to read real quotes from published authors. 